\title{
Preparation and Characterization of a New High-Performance Plastic Explosive in Comparison with Traditional Types
}

\author{
Ahmed Elbeih (D), ${ }^{1}$ Tamer Elshenawy, ${ }^{2}$ Hany Amin, ${ }^{2 \dagger}$ Ahmed K. Hussein, ${ }^{1}$ \\ and Sara M. Hammad ${ }^{3}$ \\ ${ }^{1}$ Military Technical College, Kobry Elkobbah, Cairo, Egypt \\ ${ }^{2}$ Technical Research Center, Cairo, Egypt \\ ${ }^{3}$ Faculty of Pharmacy, Cairo University, Giza, Egypt \\ ${ }^{\dagger}$ Deceased
}

Correspondence should be addressed to Ahmed Elbeih; elbeih.czech@gmail.com

Received 30 November 2018; Revised 23 February 2019; Accepted 26 February 2019; Published 2 July 2019

Academic Editor: Jose C. Merchuk

Copyright ( 2019 Ahmed Elbeih et al. This is an open access article distributed under the Creative Commons Attribution License, which permits unrestricted use, distribution, and reproduction in any medium, provided the original work is properly cited.

EPX-2R is a high-performance plastic explosive produced for different applications. EPX-2R is based on RDX (1,3,5-trinitro-1,3,5triazinane) bonded by the elastic matrix of the softened styrene butadiene binder. A computerizing mixer plastograph was used for the production of EPX-2R. The internal energy of combustion was measured and used to determine the enthalpy of formation. Friction and impact sensitivities were measured. The velocity of detonation was determined experimentally, and the detonation properties were calculated by the EXPLO 5 code. For comparison, traditional plastic explosives, composition C-4, Semtex 10, Formex P1, EPX-1, and Sprängdeg m/46, were studied. It was concluded that the velocity of detonation of EPX-2R was higher than the studied samples except composition C-4, while its sensitivity is the lowest. Interesting inversely proportional relationship between the measured internal energy of combustion and the calculated heat of detonation was observed.

\section{Introduction}

Plastic explosives are produced under different trade names by several countries. The plastic explosive consists mainly of the energetic material as filler bonded by the selected rubbery material in order to reduce the sensitivity of the explosive and improve its mechanical properties $[1,2]$. The main key in the production of the plastic explosive is the polymeric matrix. This matrix in addition to the mixing process has a significant influence on the characteristics of the produced plastic explosive [3-5]. Several publications presented the different types of plastic explosives and compared the sensitivity and the performance of the commercially available plastic explosives [6-8]. The composition of the polymeric matrix has also a significant influence on the thermal stability of the energetic materials [9-11]. Many researches discussed the decomposition kinetics of plastic explosives produced by different countries and their effect on the shelf life and the stability of the different products using variable techniques [12-16].
Composition C-4 (comp C4) is a commercial American plastic explosive including 1,3,5-trinitro-1,3,5-triazinane (RDX) as an energetic filler bonded by the softened matrix of polyisobutylene binder [17], and it has variable military applications as a destructive material [17]. Semtex 10 is a Czech plastic explosive which is used for under water blasting and demolition of rocks. It contains pentaerythritol tetranitrate (PETN) as the filler mixed with plasticized nitril rubber [18]. Formex P1 produced by France company contains a polymeric matrix of styrene butadiene rubber bond PETN explosive [19]. EPX-1 is an Egyptian plastic explosive that contains PETN explosive bonded by the nonenergetic binder, and it has been used in blasting techniques for civil applications [20]. The Sweden explosive, Sprängdeg $\mathrm{m} / 46$, contains a mixture of viscous liquid that bonded with the energetic material, PETN [20].

In this work, the production method of advanced highly energetic plastic explosive named EPX-2R was presented. The explosive properties of the new EPX- $2 \mathrm{R}$ in comparison 
with several commercial explosives, composition C-4, Semtex 10, Formex P1, EPX-1, and Sprängdeg m/46 were determined and discussed. The detonation properties of the studied materials were calculated by EXPLO5 software. The internal energy of combustion and the heat of detonation were discussed. Sensitivities of the samples to different stimuli were compared. The performance represented by the detonation velocity and detonation pressure of each sample was discussed. The effect of the energy content on the performance of the plastic explosive was also observed.

\section{Experimental}

2.1. Preparation of EPX-2R. The production of EPX-2R is performed in Heliopolis Company for Chemical Industries, Egypt. RDX with a mean particle size of 38 and $284 \mu \mathrm{m}$, respectively, is produced by the company. Dioctyl azelate (DOZ) is obtained from Sigma-Aldrich Company. Styrene butadiene binder rubber (SBR) is also product of the company.

The preparation of the polymeric matrix is based on softening of the SBR rubber by DOZ in order to obtain a viscous polymeric matrix. The production of the plastic explosive is performed in a computerizing mixer plastograph BRABENDER. The process is based on mixing of RDX with the softened SBR at two stages: 88 wt.\% of RDX was placed in the plastograph and mixed with $12 \mathrm{wt} \%$ of the softened SBR for $30 \mathrm{~min}$ at $70^{\circ} \mathrm{C}$ followed by another $40 \mathrm{~min}$ mixing under vacuum at the same temperature. The product was extruded to form the cylinder with a diameter of $21 \mathrm{~mm}$. A typical figure of the mixing process including the torque and temperature of mixing versus the mixing time is presented in Figure 1. It was observed that, at the beginning of the mixing process, the torque was high and starts to decrease by the time until it reaches a nearly stable value after $20 \mathrm{~min}$, and then a peak can be observed on the figure at $30 \mathrm{~min}$. which happened due to stopping of the mixing process in order to start the under vacuum stage. The torque starts to decrease slightly by the time until it reaches the stable value after 60 min of mixing. This result confirms the good mixing of the explosive with the polymeric matrix specially after the removing of the air voids from the mixture.

2.2. Elemental Analysis. In order to determine the $\%$ of $\mathrm{C}, \mathrm{H}$, and $\mathrm{N}$ in the produced explosive, PerkinElmer $2400 \mathrm{CHNS} / \mathrm{O}$ elemental analyzer was used. The obtained elemental analysis was recalculated in order to match the $\mathrm{N}$ content of the individual explosive and is reported in Table 1. This calculated summary formula was used as a representative of particular explosive, and so it can be used as a formula in the EXPLO5 code to determine the detonation parameters of EPX-2R.

2.3. Internal Energy of Combustion. The internal energy of combustion was measured using an Automatic Combustion Calorimeter MS10A. The process is based on ignition of the prepared sample in a bomb filled by excess of oxygen [24]. The obtained result is reported in Table 1 . The internal energy of combustion was used to calculate the heat of formation which is required for the calculation of the detonation parameters.

2.4. Impact Sensitivity Measurements. BAM impact sensitivity instrument with exchangeable drop weight was used to determine the impact energy required for initiation [25]. $50 \mathrm{~mm}^{3}$ of the sample tested and drop hammers of 2 and $5 \mathrm{~kg}$ weight were used. The probit analysis method was applied to predict the probability levels of the initiation [26]. Only the $50 \%$ probability of initiation was used and is reported in Table 2 as impact energy.

2.5. Friction Sensitivity Measurements. The sensitivity to friction was measured by the BAM friction test apparatus with the standard test conditions [25]. $0.01 \mathrm{~g}$ of the studied sample was spread on the surface of the porcelain plate where different loads were used to change the normal force between the porcelain pistil and the plate. Sound, smoke, or smell is the characteristics of the initiation of the sample. Applying the Probit analysis method [26], only the normal force at which $50 \%$ of initiations occurred is reported in Table 2 as the friction force of initiation.

2.6. Detonation Velocity Measurements. EXPLOMETFO-2000 produced by KONTINITRO AG was used to measure the detonation velocity of EPX-2R. Cylinder of $21 \mathrm{~mm}$ diameter and $200 \mathrm{~mm}$ length was prepared where three optical sensors were placed in each charge. The first sensor was placed at $50 \mathrm{~mm}$ distance from the initiator side, while the other sensors were placed at a distance of $50 \mathrm{~mm}$ from each previous sensor. Detonator no. 8 was used for the initiation process. The mean value of three measurements is recorded in Table 2.

2.7. Calculation of the Detonation Characteristics. The calculated detonation parameters (detonation velocity, $D$; heat of detonation, $Q$; detonation pressure, $P$ ) of EPX-2R and the traditional plastic explosives were calculated by the EXPLO5 thermodynamic code [28]. BKWN set of parameters for the BKW EOS was applied, and these parameters are $\alpha=0.5$, $\beta=0.298, \kappa=10.50$, and $\Theta=6620$ [29]. The calculated detonation characteristics of all the tested explosives are reported in Table 3 .

\section{Results and Discussion}

As discussed in the first part of the preparation of EPX-2R, it was observed that the conditions of mixing the ingredients affect the characteristics of the final product. The torque value was decreased until it reached a stable range where the sample had a high homogeneity, and the air gaps were removed. The results of impact and friction sensitivities are plotted in Figure 2 for comparison. Two groups of plastic explosives were observed. The first group includes Comp C4 and EPX-2R; the two plastic explosives are based on RDX, where the sensitivity of EPX-2R is lower than that 


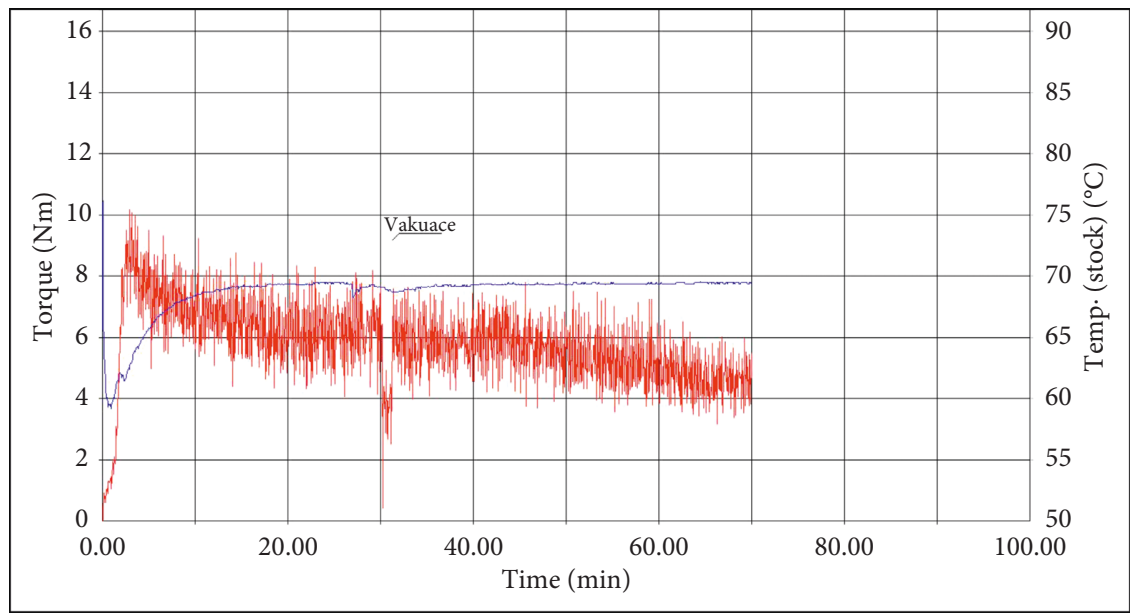

FIGURE 1: A typical mixing curve of EPX-2R. The blue line represents the temperature of the sample, while the red peaks represent the torque during the mixing process.

TABLE 1: The data required for calculation of detonation characteristics.

\begin{tabular}{lccccc}
\hline No. & Explosive type & Formula & $\begin{array}{c}\text { Molecular weight } \\
\left(\mathrm{g} \cdot \mathrm{mol}^{-1}\right)\end{array}$ & $\begin{array}{r}\text { Internal energy of } \\
\text { combustion }\left(\mathrm{J} \cdot \mathrm{g}^{-1}\right)\end{array}$ & $\begin{array}{r}\text { Heat of formation } \\
\left(\mathrm{kJ} \cdot \mathrm{mol}^{-1}\right)\end{array}$ \\
\hline 1 & Comp C4 [21] & $\mathrm{C}_{4.66} \mathrm{H}_{8.04} \mathrm{~N}_{6} \mathrm{O}_{5.99}$ & 243.97 & 12356 & 22.1 \\
2 & EPX-1 [20] & $\mathrm{C}_{7.88} \mathrm{H}_{12.36} \mathrm{~N}_{4} \mathrm{O}_{12.59}$ & 364.58 & 11528 & -666.5 \\
3 & Semtex 10 [22] & $\mathrm{C}_{8.05} \mathrm{H}_{12.64} \mathrm{~N}_{4} \mathrm{O}_{12.37}$ & 363.38 & 11942 & -646.8 \\
4 & Formex P1 [20] & $\mathrm{C}_{8.26} \mathrm{H}_{13.98} \mathrm{~N}_{4} \mathrm{O}_{11.85}$ & 358.93 & 12943 & -613.2 \\
5 & Sprängdeg m/46 [23] & $\mathrm{C}_{8.10} \mathrm{H}_{12.81} \mathrm{~N}_{4} \mathrm{O}_{10.90}$ & 340.63 & 13179 & -539.2 \\
6 & EPX-2R & $\mathrm{C}_{4.81} \mathrm{H}_{8.07} \mathrm{~N}_{6} \mathrm{O}_{6.02}$ & 246.11 & $12618 \pm 56$ & 10.6 \\
\hline
\end{tabular}

TABLE 2: The measured characteristics of the studied explosives.

\begin{tabular}{lccccc}
\hline No. & Explosive type & Impact energy $(\mathrm{J})$ & Friction sensitivity $(\mathrm{N})$ & Density $\left(\mathrm{g} \cdot \mathrm{cm}^{-3}\right)$ & ${\text { Detonation velocity measured }\left(\mathrm{m} \cdot \mathrm{s}^{-1}\right)}$ \\
\hline 1 & Comp C4 [21] & 21.1 & 214 & 1.61 & 8055 \\
2 & EPX-1 [20] & 13.9 & 176 & 1.55 & 7636 \\
3 & Semtex 10 [27] & 15.7 & 204 & 1.52 & 7486 \\
4 & Formex P1 [20] & 13.5 & 194 & 1.53 & 7544 \\
5 & Sprängdeg m/46 [23] & 14.2 & 183 & 1.52 & 7520 \\
6 & EPX-2R & 23.2 & 247 & 1.58 & $7883 \pm 63$ \\
\hline
\end{tabular}

TABLE 3: The calculated detonation characteristics of the studied explosives.

\begin{tabular}{lcccccc}
\hline No. & Explosive type & $\begin{array}{c}\text { Density } \\
\left(\mathrm{g} \cdot \mathrm{cm}^{-3}\right)\end{array}$ & $\begin{array}{c}\text { Detonation velocity } \\
\left(\mathrm{m} \cdot \mathrm{s}^{-1}\right)\end{array}$ & $\begin{array}{c}\left(D_{\text {cal }}-D_{\text {exp }}\right) / \\
\left(D_{\text {exp }} / 100\right)(\%)\end{array}$ & $\begin{array}{c}\text { Detonation pressure } \\
(\mathrm{GPa})\end{array}$ & $\begin{array}{c}\text { Detonation heat } \\
\left(\mathrm{J} \cdot \mathrm{g}^{-1}\right)\end{array}$ \\
\hline 1 & Comp C4 [21] & 1.61 & 7815 & -2.9 & 23.57 & 5512 \\
2 & EPX-1 [20] & 1.55 & 7398 & -3.1 & 21.17 & 5742 \\
3 & Semtex 10 [27] & 1.52 & 7370 & -1.5 & 20.89 & 5703 \\
4 & Formex P1 [20] & 1.53 & 7346 & -2.6 & 20.03 & 5411 \\
5 & Sprängdeg m/46 [21] & 1.52 & 7232 & -3.8 & 28 & 5345 \\
6 & EPX-2R & 1.58 & 7679 & -2.6 & 22.76 & 5493 \\
\hline
\end{tabular}

of Comp C4. The second group includes the rest of the studied plastic explosives; all of them are based on PETN as the explosive filler. The result seems logic as the sensitivity of RDX is lower than that of PETN. So the results confirm that the plastic explosives based on RDX (group 1) are lower than plastic explosives based on PETN (group 2) [30]. It is also clear that the new plastic explosive, EPX-2R, has the lowest sensitivity of all the studied plastic explosives.

On the contrary, the detonation velocities measured were plotted in Figure 3 versus the loading density of the prepared 


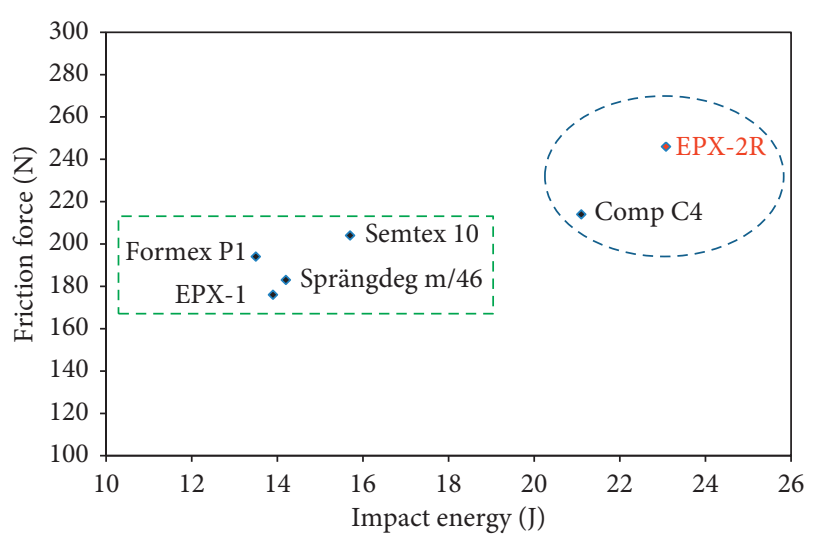

FIgURE 2: The impact and friction sensitivities EPX-2R in comparison with the studied samples.

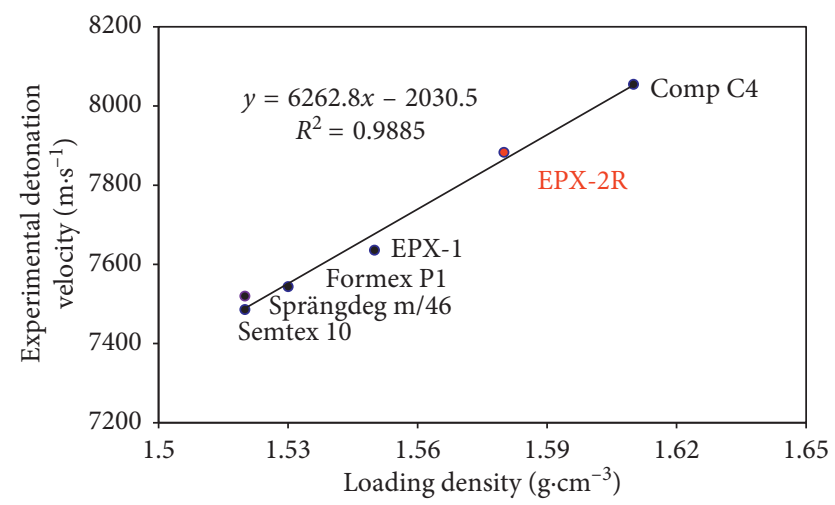

FIgURE 3: A relationship of the loading densities versus the experimental detonation velocities.

samples. This relation is well known according to the theory of explosion. The results proved that Comp $\mathrm{C} 4$ has the highest detonation velocity of all the studied samples. Actually EPX$2 \mathrm{R}$ has lower detonation velocity than Comp $\mathrm{C} 4$, but it is higher than all the other studied traditional plastic explosives. The results verify the predicted relationship with high accuracy $R^{2}=0.9885$. It also confirms the compatibility of the results of this study with the results of the references.

The calculated detonation parameters also proved that EPX-2R has higher detonation parameters than all the studied plastic explosives except Comp C4. The compatibility of the calculated results with the experimentally measured ones might be checked by presenting a relationship between the calculated detonation pressure and the experimentally measured density multiplied by square of the detonation velocity measured, as shown in Figure 4.

From Figure 4, a linear relationship was observed with lower accuracy than our prediction. The calculated detonation pressure of Formex P1 and Sprängdeg m/46 is lower than the expected from the measured values. The calculated detonation velocity of Sprängdeg $\mathrm{m} / 46$ is lower than the value of the measured detonation velocity by $3.8 \%$. This gap of calculation might be due to an error in the elemental analysis of the Sprängdeg $\mathrm{m} / 46$ sample, and it affects the compatibility of the calculated results with the measured ones. Another inverse linear relationship was observed

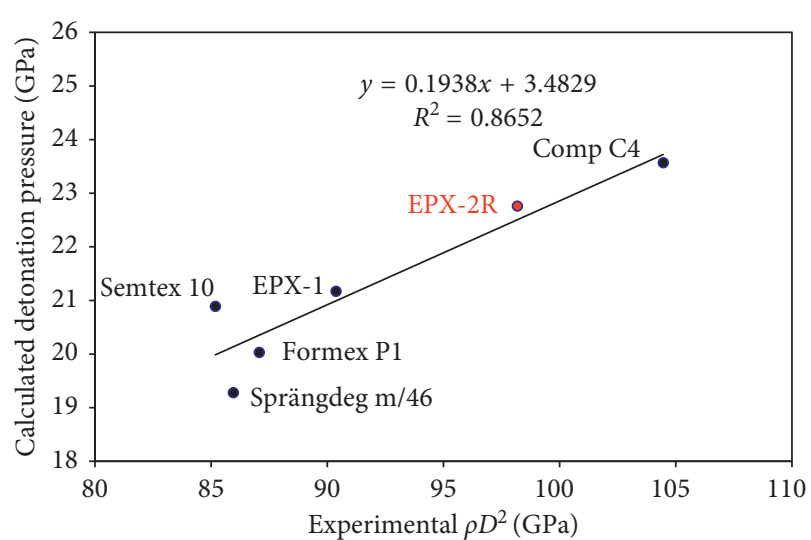

FIGURE 4: A relationship of the detonation pressure (calculated) and the experimental $\rho D^{2}$.

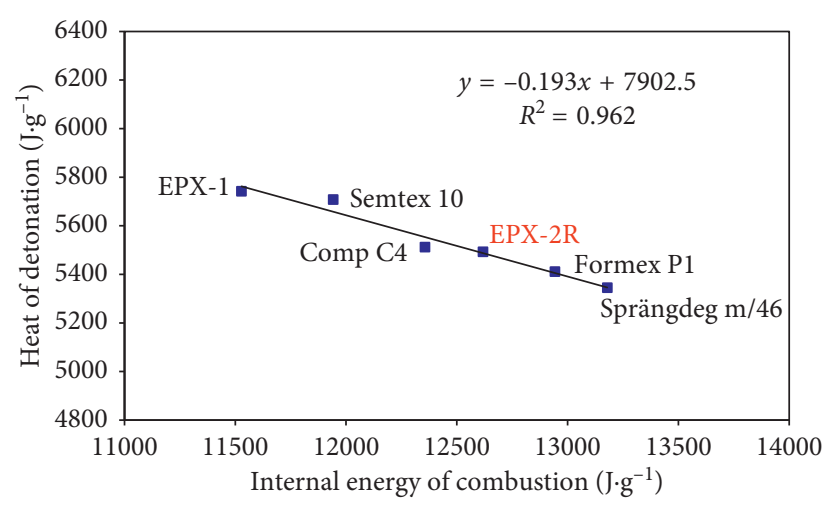

FIGURE 5: Inversely proportional relationship between the measured internal energy of combustion and the calculated heat of detonation.

between the measured internal energy of combustion and the calculated heat of detonation obtained by EXPLO5 code, as shown in Figure 5. Increasing the weight percentage of the polymer in the sample cause increase of the internal energy of combustion and in the same time decrease the heat of detonation (due to decreasing of the explosive wt.\%). The results seem logic according to the physics of explosion; it is known that increasing the weight percentage of explosives causes increasing of the detonation parameters (including the heat of detonation). Comp C4 and EPX-2R have very close heat of detonation, while the internal energy of combustion of EPX-2R is higher. This might be due to the effect of the polymeric matrix used in EPX-2R which has high energy content compared with Comp C4.

\section{Conclusion}

EPX-2R is an interesting plastic explosive; the conditions of its production affect its characteristics. Its sensitivities to different stimuli are the lowest compared with all the studied traditional plastic explosives. EPX-2R has higher detonation characteristics than the studied traditional explosives except Comp C4 which still has the highest performance of all the well-known plastic explosives. The heat of detonation of 
EPX-2R has a very close value to Comp C4. In addition, an inversely proportion relationship was observed between the measured internal energy of combustion and the calculated heat of detonation. EPX-2R is a highly energetic plastic explosive which could replace many of the commercial available plastic explosives for military and civilian applications.

\section{Data Availability}

The data used to support the findings of this study are available from the corresponding author upon request.

\section{Conflicts of Interest}

The authors declare that there are no conflicts of interest regarding the publication of this paper.

\section{Authors' Contributions}

Ahmed Elbeih was responsible for conception, foundations, and methods. Tamer Elshenawy was involved in methods and performing the experimental part. Hany Amin and Ahmed K. Hussein performed statistical analysis. Sara M. Hammad performed the experimental part.

\section{Acknowledgments}

This work was supported by the Egyptian Ministry of Military Production through research scholarships.

\section{References}

[1] T. M. Klapötke, Chemistry of High-Energy Materials, Walter de Gruyter GmbH \& Co. KG, Berlin, Germany, 2015.

[2] H.-H. Licht, "Performance and sensitivity of explosives," Propellants, Explosives, Pyrotechnics, vol. 25, no. 3, pp. 126132, 2000.

[3] X. Shi, J. Wang, X. Li, and C. An, "Preparation and characterization of HMX/Estane nanocomposites," Central European Journal of Energetic Materials, vol. 11, no. 3, pp. 433-442, 2014.

[4] P. W. Cooper, Explosives Engineering, Wiley VCH, New York, NY, USA, 1996.

[5] A. Singh, M. Kumar, P. Soni, M. Singh, and A. Srivastava, "Mechanical and explosive properties of plastic bonded explosives based on mixture of HMX and tAtB," Defence Science Journal, vol. 63, no. 6, pp. 622-629, 2013.

[6] J. P. Agrawal, High Energy Materials: Propellants, Explosives and Pyrotechnics, Wiley-VCH, New York, NY, USA, 2010.

[7] H.-S. Kim and B.-S. Park, "Characteristics of the insensitive pressed plastic bonded explosive, DXD-59," Propellants, Explosives, Pyrotechnics, vol. 24, no. 4, pp. 217-220, 1999.

[8] S. Zeman and M. Jungová, "Sensitivity and performance of energetic materials," Propellants, Explosives, Pyrotechnics, vol. 41, no. 3, pp. 426-451, 2016.

[9] A. Elbeih, M. Abd-Elghany, and T. Elshenawy, "Application of vacuum stability test to determine thermal decomposition kinetics of nitramines bonded by polyurethane matrix," Acta Astronautica, vol. 132, pp. 124-130, 2017.

[10] S. P. Felix, G. Singh, A. K. Sikder, and J. P. Aggrawal, "Studies on energetic compounds part 33. Thermolysis of keto-RDX and its plastic bonded explosives containing," Thermochimica Acta, vol. 426, no. 1-2, pp. 53-60, 2005.

[11] G. Ming-Der, W.-H. Hwu, and C.-C. Huang, "A study on the thermal decomposition of mixtures containing an energetic binder and a nitramine," Thermochimica Acta, vol. 224, pp. 127-140, 1993.

[12] M. Abd-Elghany, A. Elbeih, and S. Hassanein, "Thermal behavior and decomposition kinetics of RDX and RDX/HTPB composition using various techniques and methods," Central European Journal of Energetic Materials, vol. 13, no. 3, pp. 714-735, 2016.

[13] M. Abd-Elghany, T. M. Klapötke, A. Elbeih, and S. Zeman, "Investigation of different thermal analysis techniques to determine the decomposition kinetics of $\varepsilon-2,4,6,8,10,12$ hexanitro-2,4,6,8,10,12-hexaazaisowurtzitane with reduced sensitivity and its cured PBX," Journal of Analytical and Applied Pyrolysis, vol. 126, pp. 267-274, 2017.

[14] H. R. Pouretedal, S. Damiri, and E. F. Ghaemi, "Nonisothermal studies on the thermal decomposition of $\mathrm{C} 4 \mathrm{ex}$ plosive using the TG/DTA technique," Central European Journal of Energetic Materials, vol. 11, no. 3, pp. 405-416, 2014.

[15] A. Singh, T. C. Sharma, M. Kumar, J. K. Narang, P. Kishore, and A. Srivastava, "Thermal decomposition and kinetics of plastic bonded explosives based on mixture of HMX and TATB with polymer matrices," Defense Technology, vol. 13, no. 1, p. 24, 2017.

[16] S. Zeman, Q.-L. Yan, and A. Elbeih, "Recent advances in the study of the initiation of energetic materials using the characteristics of their thermal decomposition part II. Using simple differential thermal analysis," Central European Journal of Energetic Materials, vol. 11, no. 3, pp. 395-404, 2014.

[17] C. M. Mahoney, A. J. Fahey, K. L. Steffens, B. A. Benner Jr., and R. T. Lareau, "Characterization of composition C4 explosives using time-of-flight secondary ion mass spectrometry and X-ray photoelectron spectroscopy," Analytical Chemistry, vol. 82, no. 17, pp. 7237-7248, 2010.

[18] S. Moore, M. Schantz, and W. MacCrehan, "Characterization of three types of Semtex (H, 1A, and 10)," Propellants, Explosives, Pyrotechnics, vol. 35, no. 6, pp. 540-549, 2010.

[19] A. Wartman and B. B. Koffler, "Mouldable plastic explosives and inert simulants for mouldable plastic explosives," US 7,854,811 B1, 2010.

[20] A. Elbeih, "Characteristics of a new plastic explosive named EPX-1," Journal of Chemistry, vol. 2015, Article ID 861756, 6 pages, 2015.

[21] A. Elbeih, J. Pachman, W. A. Trzciński, S. Zeman, Z. Akštein, and J. Šelešovský, "Study of plastic explosives based on attractive cyclic nitramines part I. Detonation characteristics of explosives with PIB binder," Propellants, Explosives, Pyrotechnics, vol. 36, no. 5, pp. 433-438, 2011.

[22] A. Elbeih, S. Zeman, M. Jungová, and P. Vávra, "Attractive nitramines and related PBXs," Propellants, Explosives, Pyrotechnics, vol. 38, no. 3, pp. 379-385, 2013.

[23] A. Elbeih, S. Zeman, M. Jungova, P. Vávra, and Z. Akstein, "Effect of different polymeric matrices on some properties of plastic bonded explosives," Propellants, Explosives, Pyrotechnics, vol. 37, no. 6, pp. 676-684, 2012.

[24] M. Krupka, "Devices and equipments for testing of energetic materials," in New Trends in Research of Energetic Materials, p. 222, University of Pardubice, Pardubice, Czech Republic, 2001. 
[25] M. Suceska, Test methods for Explosives, Springer, Heideleberg, Germany, 1995.

[26] D. J. Finney, Probit Analysis, Cambridge University, Cambridge, UK, 3rd edition, 1971.

[27] A. Elbeih, M. Mokhtar Mohamed, and T. Wafy, "Sensitivity and detonation characteristics of selected nitramines bonded by Sylgard binder," Propellants, Explosives, Pyrotechnics, vol. 41, no. 6, pp. 1044-1049, 2016.

[28] M. Sućeska, "EXPLO5-computer program for calculation of detonation parameters," in Proceedings of the 32nd International Annual Conference of ICT, Karlsruhe, Germany, July 2001.

[29] M. Suceska, "Calculation of detonation parameters by EXPLO5 computer program," Materials Science Forum, vol. 465-466, pp. 325-330, 2004.

[30] A. Elbeih, T. Z. Wafy, and T. Elshenawy, "Performance and detonation characteristics of polyurethane matrix bonded attractive nitramines," Central European Journal of Energetic Materials, vol. 14, no. 1, pp. 77-89, 2017. 


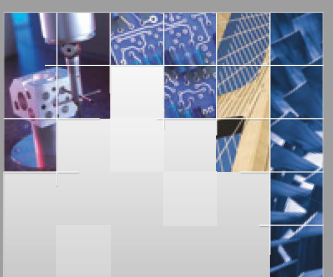

\section{Enfincering}
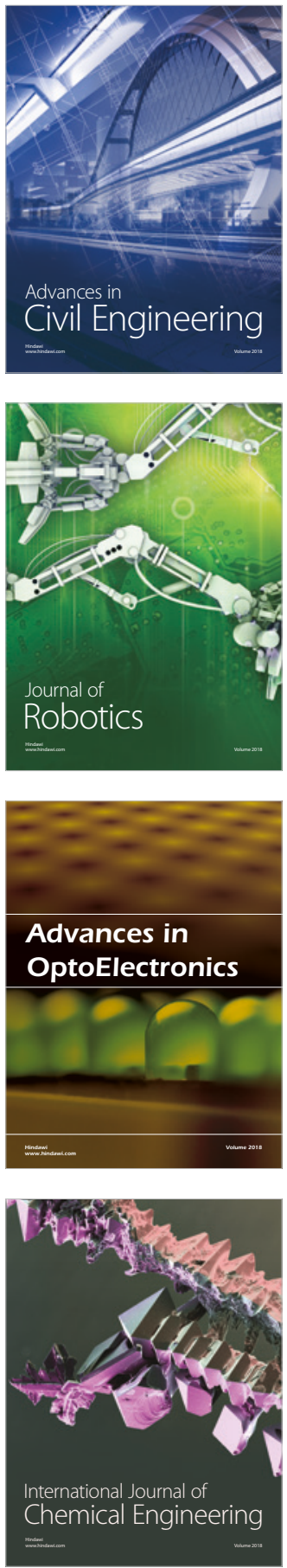

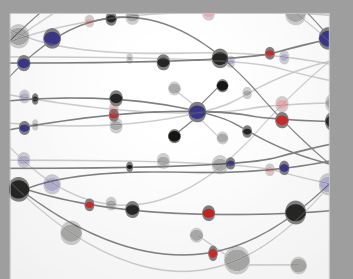

\section{Rotating \\ Machinery}

The Scientific World Journal

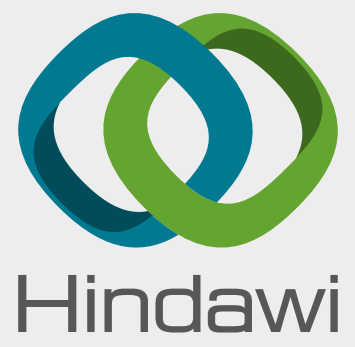

Submit your manuscripts at

www.hindawi.com
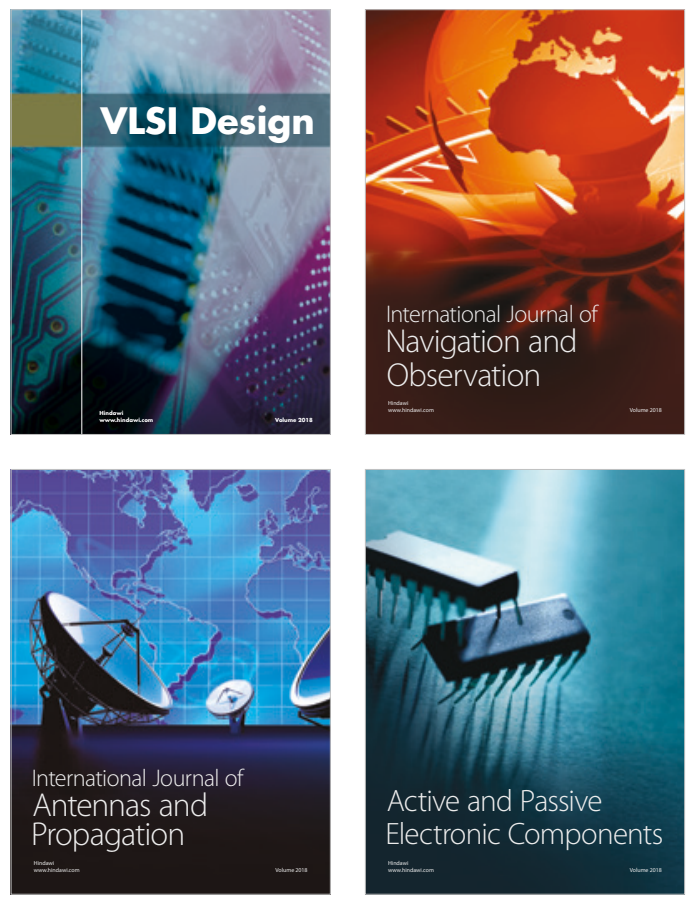
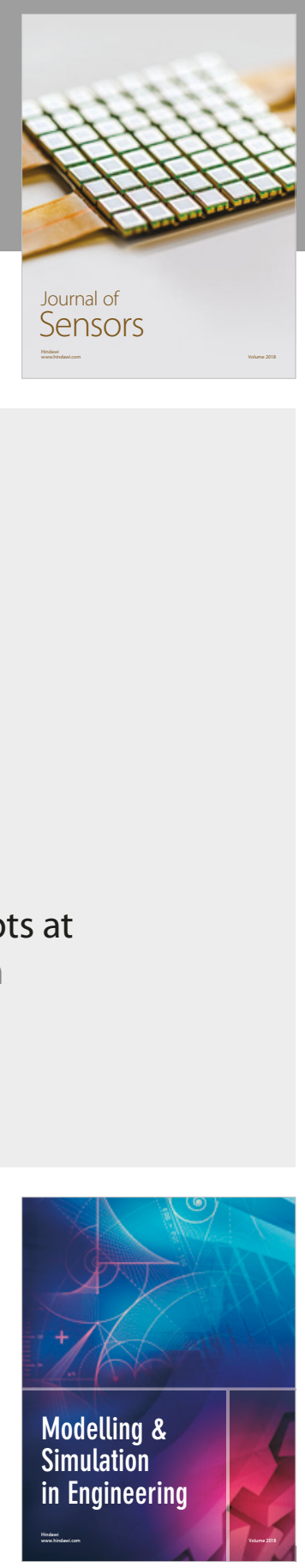

\section{Advances \\ Multimedia}
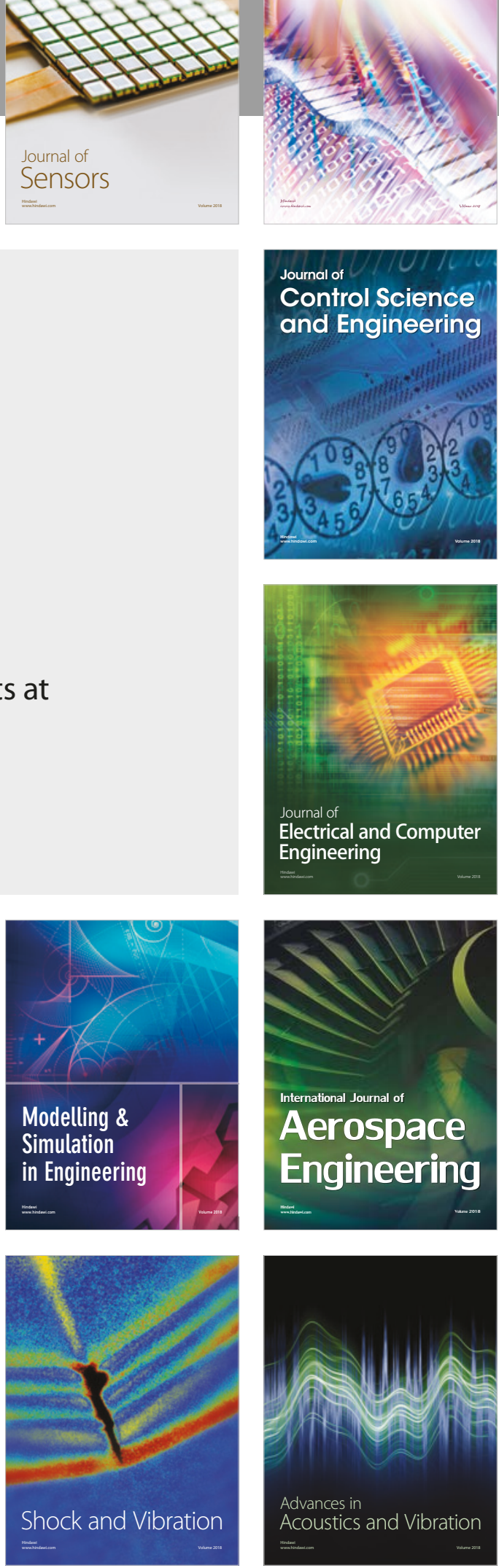